\title{
Article \\ Colorectal Cancer among Resettlers from the Former Soviet Union and in the General German Population: Clinical and Pathological Characteristics and Trends
}

\author{
Melani Ratih Mahanani ${ }^{1}\left(\mathbb{D}\right.$, Simone Kaucher ${ }^{1}$, Hiltraud Kajüter ${ }^{2}$, Bernd Holleczek ${ }^{3} \mathbb{D}$, Heiko Becher ${ }^{4}(\mathbb{D}$ \\ and Volker Winkler ${ }^{1, *(D)}$ \\ 1 Epidemiology of Transition, Heidelberg Institute of Global Health, University Hospital Heidelberg, \\ 69120 Heidelberg, Germany; melani.mahanani@uni-heidelberg.de (M.R.M.); \\ simone.kaucher@uni-heidelberg.de (S.K.) \\ 2 Cancer Registry, 44801 Bochum, Germany; Hiltraud.Kajueter@krebsregister.nrw.de \\ 3 Saarland Cancer Registry, 66119 Saarbrücken, Germany; b.holleczek@krebsregister.saarland.de \\ 4 Institute for Medical Biometry and Epidemiology, University Medical Center Hamburg-Eppendorf, \\ 20246 Hamburg, Germany; h.becher@uke.de \\ * Correspondence: volker.winkler@uni-heidelberg.de
}

check for

updates

Citation: Mahanani, M.R.; Kaucher, S.; Kajüter, H.; Holleczek, B.; Becher, H.; Winkler, V. Colorectal Cancer among Resettlers from the Former Soviet Union and in the General German Population: Clinical and Pathological Characteristics and Trends. Int. J. Environ. Res. Public Health 2021, 18, 4547. https:// doi.org/10.3390/ijerph18094547

Academic Editor: Matteo Goldoni

Received: 11 January 2021

Accepted: 23 April 2021

Published: 25 April 2021

Publisher's Note: MDPI stays neutral with regard to jurisdictional claims in published maps and institutional affiliations.

Copyright: (c) 2021 by the authors. Licensee MDPI, Basel, Switzerland. This article is an open access article distributed under the terms and conditions of the Creative Commons Attribution (CC BY) license (https:// creativecommons.org/licenses/by/ $4.0 /)$.

\begin{abstract}
This study examined time trends and clinical and pathological characteristics of colorectal cancer (CRC) among ethnic German migrants from the Former Soviet Union (resettlers) and the general German population. Incidence data from two population-based cancer registries were used to analyze CRC as age-standardized rates (ASRs) over time. The respective general populations and resettler cohorts were used to calculate standardized incidence ratios (SIRs) by time-period (before and after the introduction of screening colonoscopy in 2002), tumor location, histologic type, grade, and stage at diagnosis. Additionally, SIRs were modeled with Poisson regression to depict time trends. During the study period from 1990 to 2013, the general populations showed a yearly increase of ASR, but for age above 55, truncated ASR started to decline after 2002. Among resettlers, 229 CRC cases were observed, resulting in a lowered incidence for all clinical and pathological characteristics compared to the general population (overall SIR: 0.78, 95\% CI 0.68-0.89). Regression analysis revealed an increasing SIR trend after 2002. Population-wide CRC incidence decreases after the introduction of screening colonoscopy. In contrast the lowered CRC incidence among resettlers is attenuating to the general population after 2002, suggesting that resettlers do not benefit equally from screening colonoscopy.
\end{abstract}

Keywords: incidence; colorectal cancer; young-onset; clinical characteristics; pathological characteristics; migrants; Former Soviet Union; Germany

\section{Introduction}

The term colorectal cancer (CRC) summarizes malignancies of the colon and the rectum. In 2016, its median age of diagnosis was 76 and 72 years among German women and men, respectively [1]. The incidence of CRC started to decrease after the introduction of colon cancer screening by colonoscopy in 2002 [2]. Recently, rising CRC incidence among adolescents and young adults has attracted increased attention [3,4]. It is known that these so-called young-onset CRC tumors present distinctive clinical and pathological characteristics with lower survival compared to non-young-onset CRC cases [4-6]. An increasing prevalence of well-known CRC risk factors, such as alcohol consumption [7], red meat intake, low physical activity, cigarette smoking [8], obesity [9,10], and diabetes mellitus [11] are discussed as the main reasons. Additionally, the recommended screening age may influence the observed differences between young-onset and non-young-onset CRC, respectively [12,13]. 
Colonoscopy is a secondary prevention method that is generally offered to populations with increased age, family history of CRC syndromes, and chronic inflammatory bowel diseases $[4,14]$. Unlike other cancer screening methods aiming for early diagnosis to improve patients' outcomes, colonoscopy additionally allows removing precancerous lesions during the examination [15]. In Germany, statutory health insurance (SHI) has offered fully covered colonoscopies to people aged 55 years and above since 2002, as an alternative to the fecal occult blood test, which has been offered since 1977 [16]. In 2019, Germany lowered the recommended age for screening colonoscopies for men to 50 years, while it remained unchanged for women [17].

Ethnic German resettlers from the Former Soviet Union are the second-largest migrant group in Germany, with about 2.5 million people immigrating in large numbers in the early 1990s after the fall of the iron curtain [18]. They receive German citizenship upon arrival and are entitled to fully utilize the German healthcare system $[19,20]$. Focusing on cancer incidence and mortality compared to the general population of Germany, Kaucher et al. found that incidence and mortality of colorectal (both sexes), lung (women), prostate, and female breast cancer were lower among resettlers [21].

Considering the discussion about the increasing incidence of CRC at younger ages and the offer of screening colonoscopy, this study aims to explore the incidence of CRC and its temporal trends and to compare clinical and pathological characteristics of CRC cases between resettlers and the general German population.

\section{Materials and Methods}

We used data of two resettler cohorts, one in the administrative district of Münster (North Rhine-Westphalian) and another one in the federal state of the Saarland with the observation periods 1994 to 2013 and 1990 to 2009, respectively. The combined cohort comprised 51,311 resettlers (Saarland: 18,619; Münster: 32,692), who immigrated between 1990 and 2001 (Münster) and between 1990 and 2005 (Saarland). More details on the study population and the follow-up procedures can be found elsewhere [21,22]. The study protocol was approved by the Ethics Committee of the Medical Faculty, University Hospital Heidelberg [22].

In brief, the vital status of resettlers was derived from local population registries through record linkage or manually. The accumulated person-time was estimated for each sex, 5-year age group (up to 85+), and calendar year. For the general populations of the Saarland and Münster, person-time was ascertained from the mid-year populations provided by the federal statistic office of the Saarland and the federal cancer registry of North Rhine-Westphalian, respectively. Both population-based cancer registries provided data on CRC cases in the respective general population and the respective resettler cohort through record linkage. Incidence data included date of diagnosis, age at diagnosis, sex, tumor location (International Classification of Diseases 10th Revision (ICD-10)), tumor morphology (International Classification of Diseases for Oncology third revision (ICD O-3)), tumor grade, and stage at diagnosis. We restricted all analysis to histologically confirmed primary CRC cases (ICD-10 C18-C20) and categorized patients according to age ( $<55$ years: young-onset $C R C, \geq 55$ years: non-young-onset $C R C$ ).

The condensed stage at diagnosis coding system developed by the European Network of Cancer Registries was used to categorize tumors into a local, advanced, or unknown stage based on the status of lymph nodes $(\mathrm{N})$ and the existence of metastasis $(\mathrm{M})$ [23], due to expected missing values in population-wide registry data with varying versions of the TNM classification. Furthermore, we combined well and moderately differentiated tumors (grades 1 and 2) as low grade and poorly differentiated and undifferentiated ones (grades 3 and 4) as high grade. For three-year calendar periods, we calculated truncated age-standardized incidence rates (ASRs) separately for young-onset and non-young-onset CRC using the 1976 European standard population [24].

Afterward, we modeled the truncated ASR over time by first estimating age-specific rates with Poisson regression using the number of observed cases as the dependent variable 
and the $\log$ of the mid-year population $\mathrm{P}$ as the offset. For young-onset incidence $\mathrm{Y}$, calendar year T from 1990 to 2013 (continuous, coded from 0 to 23, starting in 1990) and age group A (categorical, 5-year age groups) were used as covariables (see formula 1).

For non-young-onset CRC incidence $Z$, an interrupted time-series approach [25] was used to detect changes due to colonoscopy screening introduced in 2002. In addition to calendar year $T$ and age group $A$, "colonoscopy" X (binary; 0: years 1990-2001, 1: years 2002-2013) and the interaction term between the calendar year and "colonoscopy" were used as covariables (see Formula (2)). Using the modeled yearly age-specific rates $Y$ and $Z$ from Formulas (1) and (2), we calculated the ASR shown in Figure 1:

$$
\begin{gathered}
\log \left(Y_{t, a}\right)=\log (P)+\beta_{0}+\beta_{1} T+\beta_{2}^{\prime} A \\
\log \left(Z_{t, a}\right)=\log (P)+\beta_{0}+\beta_{1} T+\beta_{2}^{\prime} A+\beta_{3} X_{t}+\beta_{4} T X_{t}
\end{gathered}
$$

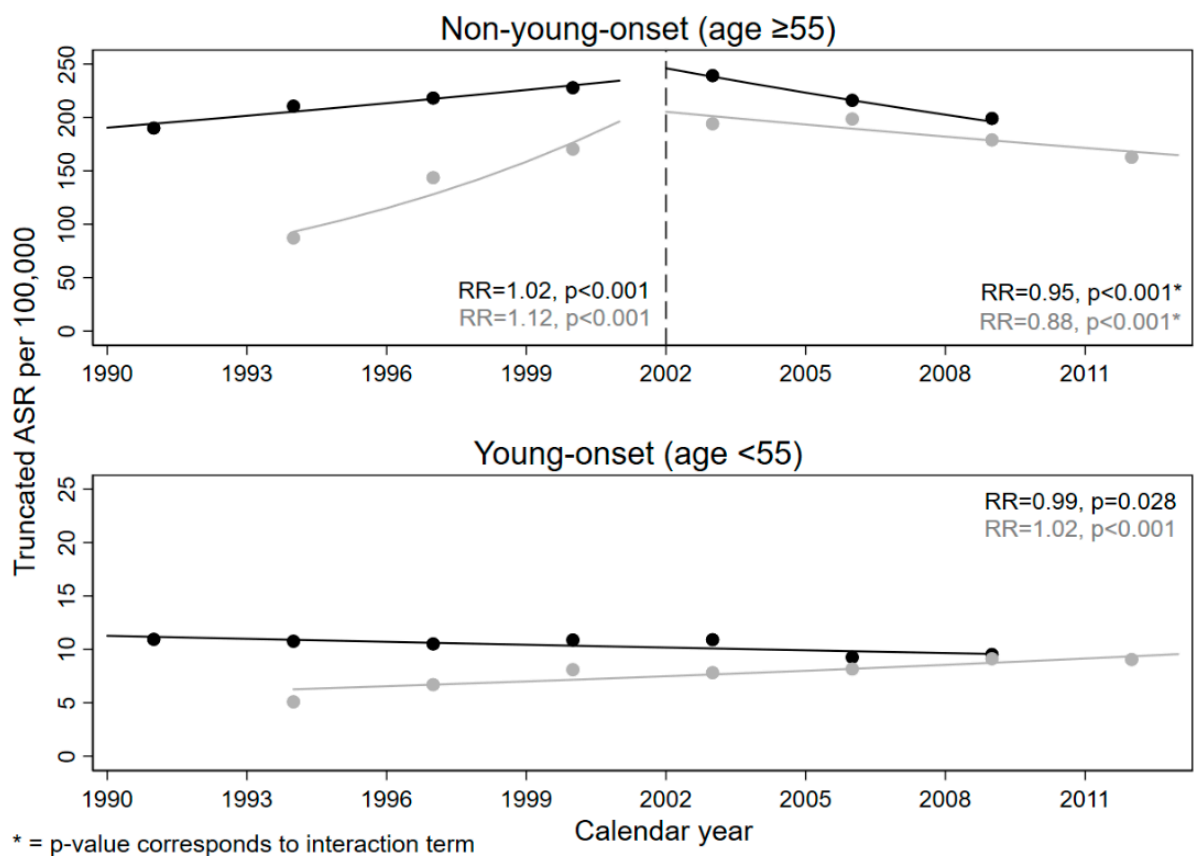

Figure 1. Observed and modeled young-onset and non-young-onset truncated ASRs of colorectal cancer incidence for the general population from 1990 to 2013; the rate ratio (RR) corresponds to the modeled calendar year effect (see Appendix A); the dashed line indicates the introduction of screening colonoscopy; black represents the Saarland population, gray the Münster population.

In the next step, we calculated standardized incidence ratios (SIRs) to compare observed CRC cases among resettlers to expected numbers in the respective host population using sex, age group, and calendar year-specific rates. SIRs were computed with exact $95 \%$ confidence intervals ( $95 \% \mathrm{CI}$ ) for all cases and before and after the introduction of colonoscopy in 2002, as well as for tumor location, grading, histology, and condensed stage at diagnosis.

We also modeled sex-specific SIRs with Poisson regression for young-onset and nonyoung onset cases separately using the number of observed cases among resettlers as the dependent variable and the log of the expected cases $E$ as the offset. For young-onset cases $U$, we used sex $S$ (binary; 0: male, 1 : female) and calendar year $T$ as covariables (see Formula (3)). For non-young-onset cases $\mathrm{V}$, the model was again extended with the covariables colonoscopy $X$ and the interaction term of the calendar year and colonoscopy (see Formula (4)):

$$
\begin{gathered}
\log \left(U_{t, s}\right)=\log (E)+\beta_{0}+\beta_{1} T+\beta_{2} S \\
\log \left(V_{t, s}\right)=\log (E)+\beta_{0}+\beta_{1} T+\beta_{2} S+\beta_{3} X_{t}+\beta_{4} T X_{t}
\end{gathered}
$$


In all Poisson models, standard errors were controlled for overdispersion [26]. Statistical analyses were performed using Stata/IC 15.1 for Windows (64-bit x86-64) Revision 21 November 2017 (StataCorp LLC, 4905 Lakeway Drive, College Station, TX 77845, USA).

\section{Results}

Between 1990 and 2013, the combined resettler cohorts comprised 666,899 person-years and 238 diagnoses with primary colorectal cancer, of which $229(96.2 \%)$ cases were histologically confirmed. In the host population, 48,980 (88.7\%) CRC cases were histologically confirmed. Demographic characteristics of patients, as well as clinical and pathological features of the included tumors among the general population and the resettlers, are summarized in Table 1. Notably, there were more young-onset CRC cases among resettlers $(22.3 \%$ vs. $10.0 \%)$. Rectal cancer was more frequently diagnosed for the general population, while among resettlers, CRC was more likely in the left colon. In both groups, most CRC cases were of other adenocarcinoma subtypes, low grade, and localized tumors.

Table 1. Demographic characteristics and clinical and pathological characteristics of CRC among resettlers and in the general population (Saarland, 1990-2009 and Münster, 1994-2013).

\begin{tabular}{|c|c|c|c|c|c|}
\hline \multicolumn{2}{|c|}{ Characteristics } & \multicolumn{2}{|c|}{ General Population } & \multicolumn{2}{|c|}{ Resettler } \\
\hline & & $\mathbf{N}$ & $\%$ & $\mathbf{N}$ & $\%$ \\
\hline \multicolumn{2}{|l|}{ Total } & 48,980 & 100.0 & 229 & 100.0 \\
\hline \multirow{2}{*}{ Region } & Saarland & 17,405 & 35.5 & 76 & 33.2 \\
\hline & Münster & 31,575 & 64.5 & 153 & 66.8 \\
\hline \multirow{2}{*}{ Time period } & 1990-2001 & 19,466 & 39.7 & 52 & 22.7 \\
\hline & 2002-2013 (colonoscopy) & 29,514 & 60.3 & 177 & 77.3 \\
\hline \multirow{2}{*}{ Young-onset } & yes (age < 55) & 4906 & 10.0 & 51 & 22.3 \\
\hline & no (age $\geq 55)$ & 44,074 & 90.0 & 178 & 77.7 \\
\hline \multirow{2}{*}{ Sex } & Female & 25,349 & 51.8 & 106 & 46.3 \\
\hline & Male & 23,631 & 48.2 & 123 & 53.7 \\
\hline \multirow{4}{*}{ Anatomic location } & Right colon & 13,123 & 26.8 & 55 & 24.0 \\
\hline & Left colon & 12,756 & 26.0 & 83 & 36.3 \\
\hline & Rectum & 15,810 & 32.3 & 66 & 28.8 \\
\hline & Other/unknown & 7291 & 14.9 & 25 & 10.9 \\
\hline \multirow{4}{*}{ Histologic Type } & Mucinous adenocarcinoma & 8463 & 17.3 & 34 & 14.9 \\
\hline & Signet-ring cell carcinoma & 311 & 0.6 & 1 & 0.4 \\
\hline & Other adenocarcinoma subtypes & 36,344 & 74.2 & 183 & 79.9 \\
\hline & Other/unknown & 3862 & 7.9 & 11 & 4.8 \\
\hline \multirow{3}{*}{ Tumor grade } & Low & 34,663 & 70.8 & 174 & 76.0 \\
\hline & High & 10,499 & 21.4 & 44 & 19.2 \\
\hline & Unknown & 3818 & 7.8 & 11 & 4.8 \\
\hline \multirow{3}{*}{ Tumor stage } & Local & 18,469 & 37.7 & 93 & 40.6 \\
\hline & Advanced & 17,404 & 35.5 & 85 & 37.1 \\
\hline & Unknown & 13,107 & 26.8 & 51 & 22.3 \\
\hline
\end{tabular}

Separated by age at onset, Figure 1 illustrates the observed and the modeled truncated ASR of the general populations. The underlying Poisson regression coefficients can be found in Appendix A.

Table 2 presents results of the SIR analyses of CRC among resettlers compared to the general population. Overall, the SIR was lower among resettlers in both cohorts and for both sexes. Resettlers showed a lower incidence of CRC according to all clinical and pathological characteristics. 
Table 2. Standardized incidence ratios of resettlers compared to the general Saarland (1990-2009) and Münster (1994-2013) population with exact $95 \%$ confidence intervals.

\begin{tabular}{|c|c|c|c|c|c|c|c|}
\hline \multirow{2}{*}{\multicolumn{2}{|c|}{ Characteristics }} & \multicolumn{2}{|c|}{ Total } & \multicolumn{2}{|c|}{ Saarland } & \multicolumn{2}{|c|}{ Münster } \\
\hline & & \multirow{2}{*}{\begin{tabular}{|l} 
Obs. \\
229
\end{tabular}} & \multirow{2}{*}{$\begin{array}{c}\text { SIR }(95 \% \text { CI) } \\
0.78(0.68-0.89)\end{array}$} & \multirow{2}{*}{$\begin{array}{c}\text { Obs. } \\
76\end{array}$} & \multirow{2}{*}{$\begin{array}{c}\operatorname{SIR}(95 \% \mathrm{CI}) \\
0.73(0.57-0.91)\end{array}$} & \multirow{2}{*}{$\begin{array}{c}\text { Obs. } \\
153\end{array}$} & \multirow{2}{*}{$\begin{array}{c}\text { SIR }(95 \% \text { CI) } \\
0.81(0.68-0.94)\end{array}$} \\
\hline Total (1990-2013) & & & & & & & \\
\hline & $1990-2001$ & 52 & $0.61(0.46-0.80)$ & 31 & $0.72(0.49-1.02)$ & 21 & $0.50(0.31-0.76)$ \\
\hline Time period & 2002-2013 (colonoscopy) & 177 & $0.85(0.73-0.98)$ & 45 & $0.74(0.54-0.98)$ & 132 & $0.89(0.75-1.06)$ \\
\hline Young-onset & Yes (age < 55) & 51 & $0.99(0.74-1.31)$ & 14 & $0.80(0.44-1.34)$ & 37 & $1.10(0.77-1.51)$ \\
\hline Young-onset & No (age $\geq 55$ ) & 178 & $0.73(0.63-0.85)$ & 62 & $0.72(0.55-0.92)$ & 116 & $0.74(0.61-0.89)$ \\
\hline \multirow{2}{*}{ Sex } & Female & 123 & $0.85(0.71-1.02)$ & 47 & $0.97(0.71-1.29)$ & 76 & $0.80(0.63-0.99)$ \\
\hline & Male & 106 & $0.70(0.58-0.85)$ & 29 & $0.52(0.35-0.75)$ & 77 & $0.81(0.64-1.02)$ \\
\hline \multirow{4}{*}{ Anatomical location } & Right colon & 55 & $0.69(0.52-0.91)$ & 15 & $0.65(0.36-1.06)$ & 40 & $0.72(0.51-0.98)$ \\
\hline & Left colon & 83 & $1.08(0.86-1.33)$ & 29 & $1.08(0.73-1.55)$ & 54 & $1.07(0.80-1.39)$ \\
\hline & Rectum & 66 & $0.68(0.53-0.87)$ & 16 & $0.45(0.26-0.73)$ & 50 & $0.82(0.61-1.08)$ \\
\hline & Others (incl. \% unknown) & $25(20)$ & $0.60(0.39-0.89)$ & $16(31.3)$ & $0.86(0.49-1.40)$ & $9(0)$ & $0.39(0.18-0.75)$ \\
\hline \multirow{4}{*}{ Histologic type } & Mucinous adenocarcinoma & 34 & $0.67(0.47-0.94)$ & 14 & $0.82(0.45-1.38)$ & 20 & $0.60(0.36-0.92)$ \\
\hline & Signet-ring cell carcinoma & 1 & $0.45(0.01-2.49)$ & 1 & $1.13(0.03-6.31)$ & 0 & $0.00(0.00-2.73)$ \\
\hline & Other adenocarcinomas & 183 & $0.83(0.71-0.96)$ & 59 & $0.73(0.56-0.94)$ & 124 & $0.88(0.74-1.05)$ \\
\hline & Others & 11 & $0.53(0.26-0.95)$ & 2 & $0.35(0.04-1.26)$ & 9 & $0.60(0.27-1.14)$ \\
\hline \multirow{3}{*}{ Tumor grade } & Low grade & 174 & $0.83(0.71-0.96)$ & 61 & $0.82(0.62-1.05)$ & 113 & $0.83(0.68-0.99)$ \\
\hline & High grade & 44 & $0.68(0.50-0.92)$ & 13 & $0.58(0.31-0.98)$ & 31 & $0.74(0.50-1.05)$ \\
\hline & Unknown & 11 & $0.57(0.29-1.03)$ & 2 & $0.29(0.03-1.04)$ & 9 & $0.73(0.34-1.40)$ \\
\hline \multirow{3}{*}{ Tumor stage } & Local stage & 93 & $0.82(0.66-1.01)$ & 26 & $0.67(0.44-0.98)$ & 67 & $0.90(0.70-1.15)$ \\
\hline & Advanced stage & 85 & $0.79(0.63-0.98)$ & 32 & $0.86(0.59-1.22)$ & 53 & $0.76(0.57-0.99)$ \\
\hline & Unknown & 39 & $0.64(0.45-0.87)$ & 18 & $0.49(0.25-0.88)$ & 28 & $0.72(0.48-1.05)$ \\
\hline
\end{tabular}

SIR, standardized incidence ratio; Obs., number of observations; CI, confidence interval. Significant results are bolded.

Modeled SIRs for CRC among resettlers are shown in Figure 2. Among non-youngonset CRC, an increasing SIR could be observed after the introduction of screening colonoscopy in 2002. Corresponding Poisson regression coefficients can be found in Appendix A.

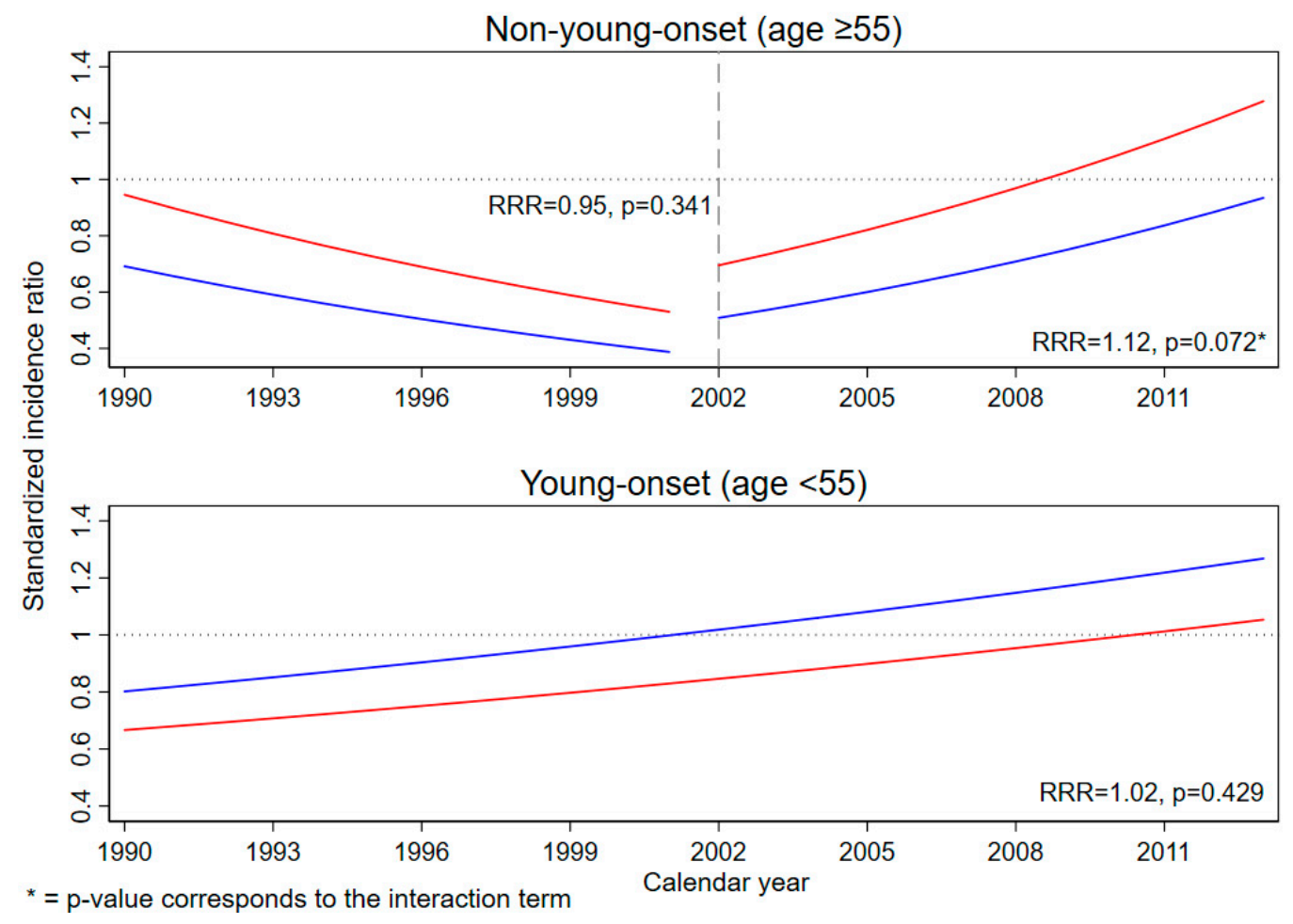

Figure 2. Modeled standardized incidence ratios for colorectal cancer among resettlers compared to the direct host populations using Poisson regression from 1990 to 2013; the relative SIR change (RRR) corresponds to the modeled calendar year effect (see Appendix A); the dashed line indicates the year of screening colonoscopy introduction; the blue line represents men, red line women. 


\section{Discussion}

This study confirmed a declining incidence in the population for which screening colonoscopy is offered in Germany. Among resettlers, the CRC incidence in older age groups was lower compared to the general population; however, for young-onset CRC, there was no difference. The lower incidence of resettlers was increasing and, therefore, attenuating to the general population after the introduction of screening colonoscopy. With respect to clinical and pathological characteristics, there were hardly any differences to the general population except for a higher frequency of left colon tumors among resettlers.

The observed increase of CRC incidence among young individuals is consistent with a number of studies from different western countries [10,27-29]. This increase may to some extent be attributed to modifiable risk factors, such as obesity and physical inactivity $[30,31]$. Additionally, low awareness of young-onset CRC among both patients and physicians and that it also occurs in those who are not subjected to family history or apparent risk factors [32] might contribute.

Left-sided CRC diagnosis is associated with rectal bleeding and changes in bowel habits [33], which may generally lead to delayed diagnoses. Additionally, a previous study suggested that male resettlers were more likely to be diagnosed with advanced tumors when looking at the most frequent cancer-sites combined (stomach, colorectal, lung, breast, and prostate cancer) [21]. However, this study does not show delayed diagnoses for CRC among resettlers. In contrast, the general German population presented a higher incidence of mucinous adenocarcinoma, which is associated with poorer clinical and pathological characteristics, such as higher grade and advanced stage at diagnosis, leading to lower survival compared to other CRC types [34].

A possible explanation for the attenuating incidence between resettlers and the general population is that risk behaviors and lifestyle adjustments to the host population are likely among migrants, as well as improved screening and diagnostic accessibility [21,35]. Resettlers may gradually adjust their lifestyle and dietary habits due to greater availability and selection of food [21]. Another explanation for the attenuating incidence might be the overtime constant CRC incidence rate among resettlers, suggesting that resettlers do not benefit from screening colonoscopy equally to the German population, which experiences decreasing rates. If resettlers do not use screening colonoscopy, they also do not benefit from the possibility to remove precancerous lesions, which may result in a higher incidence of CRC. However, the constant CRC incidence rate among resettlers (analysis not shown) might also be explained by the limited number of observations.

Our study is the first population-based study looking at time trends and clinical and pathological characteristics of young-onset and non-young-onset CRC among resettlers from the Former Soviet Union compared to Germany's general population. It needs to be stated that the analysis relies only on secondary data without information on individual risk factors, such as lifestyle, family history of CRC, etc. Furthermore, the dataset was restricted to histologically confirmed CRC cases leavening out $11.0 \%$ (young-onset: $5.2 \%$; non-young-onset: $11.9 \%$ ) of all reported CRC cases. However, there was no time trend concerning histological confirmation, and the fraction of confirmed cases was close to or above $90 \%$ except for the years 1994 to 1996 when only about $70 \%$ of all cases were histologically confirmed. Therefore, the restriction to histologically confirmed cases does not introduce bias onto the time trend analysis of the general population. Concerning the resettler cohorts, selection bias was unlikely since all ethnic Germans were invited to migrate to Germany, and during the immigration process, they were allocated quasirandomly to their first area of residence [22]. Due to data protection concerns, neither information on the date of immigration nor an individual mortality follow-up among individuals of the Münster cohort was available, which prevented us from analyzing the incidence among resettlers concerning lengths of stay in Germany. However, since most resettlers migrated to Germany in the first half of the 1990s, calendar time is highly correlated with length of stay. It should also be mentioned that the person-time of the Münster cohort had to be estimated due to an incomplete follow-up [36]. 


\section{Conclusions}

Similar to other countries, Germany is encountering a decreasing CRC incidence in the population eligible for screening colonoscopy. CRC incidence among ethnic German migrants from the Former Soviet Union is lower but continuously attenuates to the general population. This might hint towards less screening participation among resettlers, which may lead to increasing CRC incidence. However, the clinical and pathological characteristics of the resettler's tumor conditions were hardly different from the general population.

Author Contributions: H.B. and V.W. initiated the cohort studies, data were collected by V.W. and S.K. H.K. provided the incidence data for the Münster cohort. B.H. provided the incidence data for the Saarland cohort. M.R.M. did the statistical analyses. V.W. helped with the analyses. M.R.M. drafted the manuscript, and S.K., H.K., B.H., H.B., and V.W. contributed to writing and editing the manuscript and interpreting the results. All authors have read and agreed to the published version of the manuscript.

Funding: This research was funded by the German Cancer Aid (Grant Number 111232).

Institutional Review Board Statement: The study protocol was approved by the Ethics Committee of the Medical Faculty, University Hospital Heidelberg.

Informed Consent Statement: Not applicable.

Acknowledgments: We acknowledge financial support by the Deutscher Akademischer AustauschdienstGerman Academic Exchange Service (DAAD) Research Grants-Doctoral Programs in Germany, 2019/20; grant number: 57440921 .

Conflicts of Interest: The authors declare no conflict of interest.

\section{Appendix A}

Table A1. Poisson regression for modeled incidence rates displayed in Figure 1, non-young-onset CRC.

\begin{tabular}{ccccc}
\hline \multirow{2}{*}{ Variable } & \multicolumn{2}{c}{ Saarland } & \multicolumn{2}{c}{ Münster } \\
\cline { 2 - 5 } & Coefficient & $p$-Value & Coefficient & $p$-Value \\
\hline Constant & -5.79 & $<0.001$ & -6.75 & $<0.001$ \\
Calendar year & 0.02 & $<0.001$ & 0.11 & $<0.001$ \\
Age group & & $<0.001$ & & $<0.001$ \\
55-59 & -1.19 & & -1.44 & \\
$60-64$ & -0.73 & & -0.99 & \\
$65-69$ & -0.41 & & -0.62 & \\
$70-74$ & -0.16 & & -0.34 & \\
$75-79$ & 0.03 & & -0.10 & \\
$80-84$ & 0.18 & & 0.00 & \\
$85+$ & Ref. & & Ref. & \\
Colonoscopy & & & Ref. & \\
No (calendar year $<2002)$ & Ref. & & 1.46 & $<0.001$ \\
Yes (calendar year $\geq 2002)$ & 0.64 & & Ref. & \\
Colonoscopy X calendar year & & $<0.001$ & -0.13 & \\
No & Ref. & & & \\
Yes & -0.05 & & &
\end{tabular}


Table A2. Poisson regression for modeled incidence rates displayed in Figure 1, young-onset CRC.

\begin{tabular}{ccccc}
\hline \multirow{2}{*}{ Variable } & \multicolumn{2}{c}{ Saarland } & \multicolumn{2}{c}{ Münster } \\
\cline { 2 - 5 } & Coefficient & $p$-Value & Coefficient & $p$-Value \\
\hline Constant & -27.42 & 0.976 & -28.19 & 0.972 \\
Calendar year & -0.01 & 0.028 & 0.02 & $<0.001$ \\
Age group & & $<0.001$ & & $<0.001$ \\
0-4 & -20.09 & & -20.15 & \\
$5-9$ & -20.18 & & -6.42 & \\
$10-14$ & -20.24 & & -4.99 & \\
$15-19$ & -4.71 & -4.21 & \\
$20-24$ & -4.13 & -4.13 & \\
$25-29$ & -3.87 & & -3.58 & \\
$30-34$ & -3.14 & -2.77 & \\
$35-39$ & -2.11 & & -2.10 & \\
$40-44$ & -1.45 & & -1.45 & \\
$45-49$ & -0.74 & & -0.70 & \\
$50-54$ & Ref. & & Ref. & \\
\hline
\end{tabular}

Table A3. Poisson regression for standardized incidence ratios displayed in Figure 2.

\begin{tabular}{ccccc}
\hline \multirow{2}{*}{ Variable } & \multicolumn{2}{c}{ Young-Onset CRC } & \multicolumn{2}{c}{ Non-Young-Onset CRC } \\
\cline { 2 - 5 } & Coefficient & $p$-Value & Coefficient & $p$-Value \\
\hline Constant & -0.22 & 0.593 & -0.37 & 0.414 \\
Calendar year & 0.02 & 0.429 & -0.05 & 0.341 \\
Sex & & 0.455 & & 0.024 \\
Male & Ref. & & Ref. & \\
Female & -0.19 & & 0.31 & 0.113 \\
Colonoscopy & & & & \\
No (calendar year <2002) & & & -0.97 & 0.072 \\
Yes (calendar year $\geq 2002)$ & & & & \\
Colonoscopy X calendar year & & & 0.11 & \\
No & & &
\end{tabular}

\section{References}

1. Koch-Institut, R. Krebs in Deutschland Für 2015/2016; Robert Koch-Institut: Berlin, Germany, 2019.

2. Brenner, H.; Schrotz-King, P.; Holleczek, B.; Katalinic, A.; Hoffmeister, M. Declining bowel cancer incidence and mortality in Germany: An analysis of time trends in the first ten years after the introduction of screening colonoscopy. Dtsch. Ärzteblatt Int. 2016, 113, 101. [CrossRef]

3. Siegel, R.L.; Miller, K.D.; Fedewa, S.A.; Ahnen, D.J.; Meester, R.G.S.; Barzi, A.; Jemal, A. Colorectal cancer statistics, 2017. CA Cancer J. Clin. 2017, 67, 177-193. [CrossRef]

4. Ahnen, D.J.; Wade, S.W.; Jones, W.F.; Sifri, R.; Mendoza Silveiras, J.; Greenamyer, J.; Guiffre, S.; Axilbund, J.; Spiegel, A.; You, Y.N. The Increasing Incidence of Young-Onset Colorectal Cancer: A Call to Action. Mayo Clin. Proc. 2014, 89, 216-224. [CrossRef]

5. Ballester, V.; Rashtak, S.; Boardman, L. Clinical and molecular features of young-onset colorectal cancer. World J. Gastroenterol. 2016, 22, 1736-1744. [CrossRef] [PubMed]

6. Patel, S.G.; Ahnen, D.J. Colorectal Cancer in the Young. Curr. Gastroenterol. Rep. 2018, 20, 15. [CrossRef] [PubMed]

7. Fardet, A.; Druesne-Pecollo, N.; Touvier, M.; Latino-Martel, P. Do alcoholic beverages, obesity and other nutritional factors modify the risk of familial colorectal cancer? A systematic review. Crit. Rev. Oncol. Hematol. 2017, 119, 94-112. [CrossRef]

8. Johnson, C.M.; Wei, C.; Ensor, J.E.; Smolenski, D.J.; Amos, C.I.; Levin, B.; Berry, D.A. Meta-analyses of colorectal cancer risk factors. Cancer Causes Control 2013, 24, 1207-1222. [CrossRef] [PubMed]

9. Pan, S.Y.; DesMeules, M. Energy intake, physical activity, energy balance, and cancer: Epidemiologic evidence. Methods Mol. Biol. 2009, 472, 191-215. [CrossRef]

10. Edwards, B.K.; Ward, E.; Kohler, B.A.; Eheman, C.; Zauber, A.G.; Anderson, R.N.; Jemal, A.; Schymura, M.J.; Lansdorp-Vogelaar, I.; Seeff, L.C. Annual report to the nation on the status of cancer, 1975-2006, featuring colorectal cancer trends and impact of interventions (risk factors, screening, and treatment) to reduce future rates. Cancer 2010, 116, 544-573. [CrossRef]

11. Yuhara, H.; Steinmaus, C.; Cohen, S.E.; Corley, D.A.; Tei, Y.; Buffler, P.A. Is diabetes mellitus an independent risk factor for colon cancer and rectal cancer? Am. J. Gastroenterol. 2011, 106, 1911-1921, quiz 1922. [CrossRef] [PubMed] 
12. Torre, L.A.; Siegel, R.L.; Ward, E.M.; Jemal, A. Global cancer incidence and mortality rates and trends-An update. Cancer Epidemiol. Prev. Biomark. 2015, 25, 16-27. [CrossRef] [PubMed]

13. Jung, Y.S. Is colorectal cancer screening necessary before 50 years of age? Intest. Res. 2017, 15, 550-551. [CrossRef]

14. Bibbins-Domingo, K.; Grossman, D.C.; Curry, S.J.; Davidson, K.W.; Epling, J.W.; García, F.A.; Gillman, M.W.; Harper, D.M.; Kemper, A.R.; Krist, A.H. Screening for colorectal cancer: US Preventive Services Task Force recommendation statement. JAMA 2016, 315, 2564-2575. [PubMed]

15. Austin, H.; Henley, S.J.; King, J.; Richardson, L.C.; Eheman, C. Changes in colorectal cancer incidence rates in young and older adults in the United States: What does it tell us about screening. Cancer Causes Control 2014, 25, 191-201. [CrossRef]

16. Brenner, H.; Altenhofen, L.; Stock, C.; Hoffmeister, M. Prevention, early detection, and overdiagnosis of colorectal cancer within 10 years of screening colonoscopy in Germany. Clin. Gastroenterol. Hepatol. 2015, 13, 717-723. [CrossRef]

17. Bundesausschuss, G. Beschluss des Gemeinsamen Bundesausschusses über eine Richtlinie für Organisierte Krebsfrüherkennungsprogramme und eine Änderung der Krebsfrüherkennungs-Richtlinie. Decision of the Federal Joint Committee on a Directive of Organized Cancer Screening Programs and an Amendment to the Cancer Screening Directive; Federal Joint Committee: Berlin, Germany, 2018.

18. Bundesverwaltungsamt. (Spät-)Aussiedler und Ihre Angehörigen Zeitreihe 1950-2017; Herkunftsstaaten: Cologne, Germany, 2017.

19. Bundesamt, S. Bevölkerung und Erwerbstätigkeit; Statistisches Bundesamt: Wiesbaden, Germany, 2018.

20. Kaucher, S.; Deckert, A.; Becher, H.; Winkler, V. Migration pattern and mortality of ethnic German migrants from the former Soviet Union: A cohort study in Germany. J. BMJ Open 2017, 7, e019213. [CrossRef] [PubMed]

21. Kaucher, S.; Kajüter, H.; Becher, H.; Winkler, V. Cancer Incidence and Mortality among Ethnic German Migrants From the Former Soviet Union. Front. Oncol. 2018, 8, 378. [CrossRef] [PubMed]

22. Winkler, V.; Kaucher, S.; Deckert, A.; Leier, V.; Holleczek, B.; Meisinger, C.; Razum, O.; Becher, H. Aussiedler Mortality (AMOR): Cohort studies on ethnic German migrants from the Former Soviet Union. BMJ Open 2019, 9, e024865. [CrossRef]

23. Berrino, F.; Brown, C.; Moller, T.; Sobin, L.; Faivre, J. ENCR Recommendations-Condensed TNM for Coding the Extent of Disease. Lyon Eur. Netw. Cancer Regist. 2002, 2-5.

24. Pace, M.; Lanzieri, G.; Glickman, M.; Zupanič, T. Revision of the European Standard Population: Report of Eurostat's Task Force; Publications Office of the European Union: Luxembourg, 2013.

25. Bernal, J.L.; Cummins, S.; Gasparrini, A. Interrupted time series regression for the evaluation of public health inter-ventions: A tutorial. Int. J. Epidemiol. 2017, 46, 348-355, Corrigendum to 2020, 49, 1414.

26. McCullagh, P.; Nelder, J. Generalized Linear Models, 2nd ed.; Chapman and Hall: New York, NY, USA, 1989.

27. Liang, J.; Kalady, M.F.; Church, J. Young age of onset colorectal cancers. Int. J. Colorectal Dis. 2015, 30, 1653-1657. [CrossRef] [PubMed]

28. Young, J.P.; Win, A.K.; Rosty, C.; Flight, I.; Roder, D.; Young, G.P.; Frank, O.; Suthers, G.K.; Hewett, P.J.; Ruszkiewicz, A. Rising incidence of early-onset colorectal cancer in A ustralia over two decades: Report and review. J. Gastroenterol. Hepatol. 2015, 30, 6-13. [CrossRef]

29. Siegel, R.L.; Torre, L.A.; Soerjomataram, I.; Hayes, R.B.; Bray, F.; Weber, T.K.; Jemal, A. Global patterns and trends in colorectal cancer incidence in young adults. Gut 2019, 68, 2179-2185. [CrossRef]

30. Russo, A.; Franceschi, S.; La Vecchia, C.; Dal Maso, L.; Montella, M.; Conti, E.; Giacosa, A.; Falcini, F.; Negri, E. Body size and colorectal-cancer risk. Int. J. Cancer 1998, 78, 161-165. [CrossRef]

31. Aleksandrova, K.; Schlesinger, S.; Fedirko, V.; Jenab, M.; Bueno-de-Mesquita, B.; Freisling, H.; Romieu, I.; Pischon, T.; Kaaks, R.; Gunter, M.J. Metabolic mediators of the association between adult weight gain and colorectal cancer: Data from the European Prospective Investigation into Cancer and Nutrition (EPIC) cohort. Am. J. Epidemiol. 2017, 185, 751-764. [CrossRef]

32. O'Connell, J.B.; Maggard, M.A.; Livingston, E.H.; Cifford, K.Y. Colorectal cancer in the young. Am. J. Surg. 2004, 187, 343-348. [CrossRef]

33. Richman, S.; Adlard, J. Left and right sided large bowel cancer. BMJ 2002, 324, 931-932. [CrossRef]

34. Kang, H.; O'Connell, J.B.; Maggard, M.A.; Sack, J.; Ko, C.Y. A 10-year outcomes evaluation of mucinous and signet-ring cell carcinoma of the colon and rectum. Dis. Colon Rectum 2005, 48, 1161-1168. [CrossRef] [PubMed]

35. Arnold, M.; Razum, O.; Coebergh, J.-W. Cancer risk diversity in non-western migrants to Europe: An overview of the literature. Eur. J. Cancer 2010, 46, 2647-2659. [CrossRef] [PubMed]

36. Becher, H.; Winkler, V.J. Estimating the standardized incidence ratio (SIR) with incomplete follow-up data. BMC Med. Res. Methodol. 2017, 17, 55. [CrossRef] 